\title{
Development of a Novel Insecticide, Dinotefuran*
}

\author{
Takeo WAKITA, ** Naoko YASUI, Eiichi YAMADA and Daisuke KISHI \\ Functional Chemicals Laboratory, Mitsui Chemicals, Inc., 1144 Togo Mobara, Chiba 297-0017, Japan
}

(Accepted March 2, 2005)

\begin{abstract}
Dinotefuran is a new neonicotinoid developed by Mitsui Chemicals and first registered in Japan in 2002 under the trade name of Starkle ${ }^{\circledR}$ and Albarin ${ }^{\circledR}$. It has a characteristic tetrahydro-3-furylmethyl group instead of the aromatic heterocyclic ring that was previously considered indispensable for insecticidal activity of neonicotinoids. Dinotefuran was discovered by research using acetylcholine as the lead compound by way of a 3methoxypropyl compound and its cyclization. It has excellent insecticidal properties and offers excellent control of a wide variety of pests in many kinds of crops. (C) Pesticide Science Society of Japan
\end{abstract}

Keywords: dinotefuran, neonicotinoid, acetylcholine.

\section{INTRODUCTION}

Neonicotinoids are a promising class of insecticides with excellent chemical and biological properties, such as wide spectrum, low application rate, and quick uptake and translocation in plants. These agents all have a pyridine ring or a thiazole ring considered indispensable to this chemical class because the action mechanism and structure are similar to those of nicotine. In 1992, we started researching a new neonicotinoid using acetylcholine as the lead compound, which acts on the same receptor as nicotine but does not have hetero rings. As a result of this approach, we found dinotefuran, which has a characteristic tetrahydro-3-furylmethyl group instead of the pyridine-like rings of other neonicotinoids.

This paper presents a short history of its discovery and characterization of dinotefuran.

\section{DISCOVERY}

A structural similarity between acetylcholine and neonicotinoids is the distance between the hydrogen acceptor site (HA site) and the cationic site, which is suitable for binding to nicotinic acetylcholine receptors (nAChRs). First, we modified the quarternary ammonium cation of acetylcholine into the (nitromethylene) imidazolidine which was expected to exhibit high insecticidal activity. As for the HA site, we assumed the optimal position of an oxygen atom, which is the binding point to nAChRs, to be at a length of two to three

\footnotetext{
* See Part II for the full Japanese article.

** To whom correspondence should be addressed. (C) Pesticide Science Society of Japan
}

methylene chains from the nitrogen atom on the imidazolidine ring. We synthesized a series of compounds with straight carbon chains and evaluated their insecticidal activity. Although strong activity was not found in these compounds, we recognized two pieces of important information; 1) compounds with three methylene units showed higher activity than those with two methylene units, and 2) the ether form showed the highest activity among straight-chain compounds. From these results, we selected the 3-methoxypropyl compound as the next lead compound.

As a following step, we converted the straight chain ether compound to a cyclic ether compound in order to change the direction of the lone-pair electron of the oxygen atom and fix the location of the oxygen atom. We synthesized cyclic ether compounds and found a tetrahydro-3-furylmethy group, that showed more than 10 times the activity of the 3methoxypropyl compound.

As the next step, the HA site was fixed to the tetrahydro-3furylmethy group, and the cationic site was changed to other partial structures of the known neonicotinoids. Among these compounds, we chose the most active compound, dinotefuran, which has the tetrahydro-3-furylmethy group as the HA site and a nitroguanidine moiety as the cationic site.

\section{STRUCTURE-ACTIVITY RELATIONSHIPS}

The structure-activity relationships of dinotefuran analogues against Nephotettix cincticeps and Laodelphax striatellus are summarized as follows.

1) The non-substituted compound on the tetrahydro-3furylmethy group exhibited the highest insecticidal activity. Introduction of a methyl group at the 4- or 5- position gave 
intermediate activity and that at the 2- or 3-position reduced the activity significantly.

2) A methyl group on nitroguanidine was best for the activity among alkyl groups.

3) Acyl groups on the nitroguanidine were as effective as the unsubstituted compound.

\section{PROPERTY}

Dinotefuran exhibits a insecticidal activity against Hemiptera, Lepidoptera, Coleoptera, Diptera, Dictyoptera and Thysanoptera. Furthermore, it has very low phytotoxicity so that it can be utilized for many kinds of crops.

Dinotefuran is water-soluble and has excellent systemic and translaminar action in many plants. This property enables dinotefuran to be applied using various methods and various formulations.

The binding assay using insect nAChRs and the electrophysiological study showed that dinotefuran acted on nAChRs as an agonist. However, in the binding study, the affinity of dinotefuran against the binding site of other neonicotinoids was very low, suggesting that this compound acts on a different site than other neonicotinoids.

\section{PHYSICAL AND CHEMICAL PROPERTIES}

Common name: dinotefuran

Trade name: Starkle ${ }^{\circledR}$, Albarin ${ }^{\circledR}$

Experimental name: MTI-446

Chemical name: $(R S)$-1-methyl-2-nitro-3-(tetrahydro-3furyl-methyl)guanidine

Molecular formula: $\mathrm{C}_{7} \mathrm{H}_{14} \mathrm{~N}_{4} \mathrm{O}_{3}$
Molecular weight: 202.21

Appearance: colorless crystal

Melting point: $107.5^{\circ} \mathrm{C}$

Vapour pressure: $<1.7 \times 10^{-6} \mathrm{~Pa}\left(30^{\circ} \mathrm{C}\right)$

Partition coefficient: $\log P_{\text {ow }}=-0.549\left(25^{\circ} \mathrm{C}\right)$

Solubility (water): $40 \mathrm{~g} / 1\left(\mathrm{pH} 7,20^{\circ} \mathrm{C}\right)$

\section{SAFETY}

The results of toxicological and ecotoxicological studies demonstrated that dinotefuran has a very low toxicity in mammals, birds and acuatic animals.

Toxicology

Acute oral $\left(\mathrm{LD}_{50}\right)$ rat male $: 2804 \mathrm{mg} / \mathrm{kg}$, female: $2000 \mathrm{mg} / \mathrm{kg}$ mouse male : $2450 \mathrm{mg} / \mathrm{kg}$, female: $2275 \mathrm{mg} / \mathrm{kg}$ Acute dermal $\left(\mathrm{LD}_{50}\right)$ rat male/female: $>2000 \mathrm{mg} / \mathrm{kg}$ Skin sensitizing (guinea pig): non-sensitizing Eye irritation (rabbit): slightly irritating Teratogenicity oral (guinea pig, rabbit): negative Carcinogenicity feed (rat, mouse): non-carcinogen

Genotoxicity (Ames test, Chromosomal aberration and Mouse micronucleus): negative

Ecotoxicology

Avian toxicity

Japanese quail (acute oral $\mathrm{LD}_{50}$ ): $>2000 \mathrm{mg} / \mathrm{kg}$

Mallard duck (acute dietary $\mathrm{LD}_{50}$ ): $>1301 \mathrm{mg} / \mathrm{kg}$

Aquatic toxicology

Carp $\left(96 \mathrm{hr}, \mathrm{LD}_{50}\right):>100 \mathrm{ppm}$

Daphnia $\left(48 \mathrm{hr}, \mathrm{EC}_{50}\right):>1000 \mathrm{ppm}$

$\operatorname{Alga}\left(72 \mathrm{hr}, \mathrm{EC}_{50}\right):>100 \mathrm{ppm}$ 